\title{
Study on the Linkage Development between Manufacturing Industry and dry ports Logistics of Xi'an
}

\author{
Congli Xie $\mathrm{X}^{1, \mathrm{a}}$ \\ ${ }^{1}$ Bussiness School , Xi'an International University, Xi'an,710077, China \\ email:54471753@qq.com
}

Keywords: Manufacturing Industry; dry ports Logistics; Linkage

\begin{abstract}
In recent years, the close relationship between the manufacturing industry and logistics industry has been paid more extensive attention, how to achieve the two friendly development, it has a very importance practical significance to accelerate the manufacturing industry transformation, and reduce all kinds of products circulation time and circulation cost and enhance the competitiveness of manufacturing enterprises and its products. This article, based on the Xi'an manufacturing industry and the dry ports logistics, by analyzing the two operators of the status quot, finally puts forward some improvement strategies for the development of this linkage.
\end{abstract}

\section{Introduction}

Manufacturing industry as an important pillar industry, it can promote the development of logistics industry, and the logistics industry development can protect and promote the optimization and upgrading of the manufacturing sector. Strengthen the linkage between manufacturing and logistics industry. On the one hand, it can enhance the core competitiveness of the manufacturing sector, and accelerate the transformation of manufacturing industry; On the other hand, it can also promote the development of the logistics industry to further promote the development of the manufacturing sector[1]. Modern logistics and manufacturing industry are promoting each other, and developing commonly. It is the important way of industrial structure adjustment and rapid economic growth[2] by strengthening the linkage development and contact of logistics industry and the manufacturing industry and improving the effective communication between the two. As an important industrial base in Northwest China, Xi'an covers high-tech industries, equipment manufacturing industry and national defense science and technology industries, such as Shaanxi Heavy Duty Automobile Co. Ltd, Sima motor, Sinosteel etc. A number of major projects, such as major equipment manufacturing household items BYD car project, Fast heavy transmission project, Eurostar bus and car chassis construction projects are also in the planning and construction; the renovation of these key enterprises and the investment cooperation of key projects are changing the cooperation mode between Xi'an manufacturing enterprises and logistics enterprises.

As a comprehensive transportation hub and major cargo distribution center, Xi'an dry ports is helpful to promote the rapid development of the manufacturing sector, and maximize transports efficiency, and reduce manufacturing logistics costs with its perfect road, rail transports network and integrated logistics services.

\section{The Linkage Between Logistics and Manufacturing Industry}

\section{- Manufacturing industry is the foundation and precondition of the development of logistics industry.}

Goods supply is the lifeline of the logistics enterprise, adequate supply of goods can help the logistics enterprises to achieve economies of scale, reduce operating costs, improve the competitiveness of enterprises. The development of manufacturing industry can drive the logistics demand of raw material market, semi finished product and finished product market, so as to drive the development of the whole logistics industry[3]. The development of manufacturing industry can drives the supply chain upstream and downstream enterprises development, thus to improve the material flow in a greater scope, so as to bring a more adequate supply of goods for the logistics 
industry, which is helpful to improve the operation efficiency of the logistics industry, and reduce the cost, so as to better serve the manufacturing enterprises.

\section{- Logistics industry provides a guarantee for the development of manufacturing industry.}

Manufacturing enterprises from the supply, production, sales and even recycling and other aspects can not be separated from the protection and supports of the logistics, so the rapid transformation development of the manufacturing sector can not be separated from the logistics industry supports. The efficient development of the logistics industry will help to upgrade the manufacturing industry, reduce manufacturers logistics costs, improve the speed of material supply and supply security, can it can help to improve the competitiveness of manufacturing enterprises.

\section{- Linkage is the inevitable trend of the development of manufacturing and logistics industry}

To realize the socialization and specialization,the logistics industry will be effective linkage with the manufacturing industry, the realization of the socialization of logistics is an important condition for the rapid development of manufacturing industry and the only way[4]. Manufacturing and logistics industry are interdependent and complement each other, joint manufacturing and logistics industry can promote the optimization of the logistics industry restructuring and upgrading, Synergies between manufacturing and logistics industry linkage development is the inevitable trend of the future development of the two.

\section{Meaning of the linkage development between manufacturing and dry ports of Xi'an}

\section{- Be conducive to the Core Strengths of Manufacturing Enterprises in Xi'an}

Manufacturing enterprise business is divided into 6 parts, research and development, raw materials procurement, manufacturing and processing, warehousing and distribution, marketing, after-sales service. The traditional vertical integration can not adapt to the development needs of the current manufacturing enterprises. In order to become bigger and stronger, enterprises manufacturing enterprises must highlight the specialized division of labor and cooperation to enhance its core competitiveness by outsourcing logistics.Therefore, choosing a specialization, strong logistics service providers can help manufacturing industry to enhance competitiveness, and achieve better economic benefits.

\section{- Contribute to market expansion and cost control in manufacturing in Xi'an}

General merchandise processing time will not exceed 10\%, while the time required by logistics is more than $90 \%$. In Europe and the United States manufacturing enterprise, the proportions of logistics costs accounts for about 8\%, Japan is only 5\%, while the average processing time of Xi'an manufacturing enterprise products is $10 \%-15 \%$. Thus, if we can achieve the seamless link of the logistics and manufacturing and shorten the time of the circulation of materials, it can effectively shorten the lead time, reduce the cost of circulation, enhance the competitiveness of their products, thus it will be contributing to Xi'an manufacturing enterprises to open up the market and cost control[5].

\section{- To provide power for the development of Xi'an ports logistics}

dry ports as a comprehensive logistics platform,, its development depends on the healthy and orderly development of dry ports of the region in various industries, while expanding and escalating scale of manufacturing industries is undoubtedly injected new vitality for the development of dry ports, but also bring new impetus for the vigorous development of dry ports economy . Therefore, the development of Xi'an manufacturing industry is largely contributed to the development of Xi'an dry ports. Therefore, in order to achieve rapid growth in the regional economy, it is necessary to realize the coordinated development of dry ports and manufacturing industry. 


\section{Problems existing in joint development of Xi'an manufacturing and dry ports}

From the current overall situation, the development between Xi'an manufacturing and dry ports is not very coordinated, the linkage effect is not obvious.Xi'an dry ports service capacity for manufacturing enterprise is far from enough, the most frequent problems is operating properly, the more lower level of competition, without studying new ways, the most serious is the lack of thorough awareness of integrated logistics services, and no innovative solutions.

\section{- The importance of manufacturing industry and dry ports logistics is not enough}

A serious lack of awareness of linkage development of Xi'an manufacturing industry and logistics industry, most enterprises haven't yet broken the original vertical integration of self operation mode, and do not have a deep understanding of dry ports logistics has an important influence on manufacturing industry. these cause the slow development of the manufacturing industry and the ports logistics, poor integration of resources, low level of bilateral cooperation.

\section{- Smaller proportion of Xi'an dry ports Logistics}

In Xi'an, the vast majority of manufacturing enterprise logistics business model is self-employed. China's outsourcing ratio is about $16 \%$, but the proportion of outsourcing in Xi'an less than $10 \%$. Except for a few parts of the enterprise material procurement, product sales are outside with other logistics companies combination, other logistics are taken in the form of self-logistics, the ratio of dry ports logistics is even low .

\section{- Insufficient logistics service capacity of Xi'an dry ports}

The overall size of the logistics enterprises in Xi'an area is small. In the national 737 class a logistics enterprises, while Xi'an accounted for less than ten enterprises. Xian dry ports as a important integrated logistics platform of Shaanxi and even western, logistics quantity and quality of the enterprises settled in are significantly behind the developed coastal area, and from the service functions, more enterprises are providing a single traditional logistics services, such as transportation, warehousing, distribution,etc., and logistics enterprises exist serious competition of product homogenization , small supply capacity, and the uneven-service level, which is mismatch with the need of the integration of production and marketing service of manufacturing enterprises.

\section{- Lack of public information platform}

Logistics information is very important to the development of enterprises, Xi'an manufacturing industry and dry ports logistics linkage development information platform construction is lagging behind, manufacturing and logistics platform for building their own company,and did not achieve complete docking. Which results in asymmetric information, poor communication channels, and fail to realize the information real-time effective sharing and the reasonable utilization of resources and so on.

Countermeasures for the linkage development of $\mathrm{Xi}$ 'an manufacturing industry and the logistics of dry ports

\section{- Strengthen the awareness of linkage of manufacturing industry and dry ports}

Manufacturing enterprises and land ports enterprises must constantly strengthen the linkage consciousness, understand the importance of the advantages complementary relationship between dry ports logistics and manufacturing enterprise from the point of view of the supply chain and take this relationship into all aspects of business management, break through the original single isolated enterprise's management thought, strengthen the close cooperation between the two, to maximize the resources to achieve the effective sharing.

\section{- Establishing the linkage working mechanism}

In order to achieve better coordinated development of Xi'an manufacturing industry and the 
Madrid and dry ports logistics, the government's participation and supports is always needed. First of all, the relevant departments of the government should recognize the importance role of manufacturing industry and the dry ports logistics for the development of Xi'an, take the linkage development of manufacturing industry and the dry ports logistics as the top priority of the economic development of Xi'an. In addition, in the economic area Xi'an must actively establish linkage work rules for manufacturing industry and dry ports logistics, which not only can take advantage of their own ,but also can be combined with the logistics facilities to study new policy and suggestions[6]. Finally, Xi'an should gradually form a set of efficient, fast, complete, supporting logistics service system for integration. For example, charring about pilot work with Xi'an manufacturing industry and dry ports logistics industry linkage development, choosing different brand enterprises (such as Li Jun, XAC)in different industries (such as in the automotive, aerospace, etc.) , using government supports as well as some good projects to complete this pilot work.

\section{- Introduction of linkage supports policy}

Constantly made and put on the policies and regulations for mutual supports of the manufacturing industry and the dry ports Logistics. while encouraging the manufacturing industry and international dry ports logistics to probe theory research, and construct practice and key projects. The second is to encourage a variety of institutional investors and investment guarantee agencies guarantee for linkage development for manufacturing and dry ports logistics in order to reduce the pressure on the construction and operation of the project investment and financing.

\section{- Continuously improving outsourcing proportion of manufacturing logistics}

To realize the joint development of manufacturing industry and dry ports logistics, to make the social logistics have more development space, we must realize the socialization of logistics demand of manufacturing enterprises, and make the demand to maximize the gathering and release. This will encourage the manufacturing enterprises to break through the old ideas,to constantly optimize the business process, to realize manufacturing enterprise specialized division of labor, to separate logistics business from manufacturing industry, and to establish the logistics of the capital projects, offer a positive words and ideas for new logistics management, according to their own needs, the enterprises should find and create favorable conditions and opportunity to serve the needs of their own by the most effective management system[7].

\section{- Speed up the construction of information platform.}

To achieve an effective interface between manufacturers and logistics of dry ports, we must first solve the problem of information in a timely manner. Therefore, it is necessary to establish both linkage information platform, all information from the dry ports enterprises, manufacturing enterprises and their upstream and downstream of each enterprise realize the complete sharing, by building a platform, all kinds of information can achieve a seamless docking and ensure the smooth flow of information channels, which is the basis to establish the linkage between the two.

\section{Acknowledgment}

In this paper, the research was sponsored by Social Science Fund Project of Shaanxi Province (Project No. 2015D060) and Shaanxi Provincial Department of Education Science Research Project (Project No. 2016JK2158).

\section{References}

[1] PAOLO GUERRIERI, VALENTINA MELICIANI.Technology and International competitiveness:the inter dependence between manufacture ingenious producer service[J] .Structure Change and Economic Dynamics,2005, 16: 489 -502.

[2]MASANAO AOKI, HIROSHIYOSHIKAWA. Demand saturation creation and economic growth[J] .Journal of Economic Behavior \& Organization, 2002, 48: 127 -154. 
[3]Xian Chen,Jianfeng Huang.Division of Labor, Interactions and Convergence: An Empirical Study of the relationship between the evolution of services and manufacturing[J].China Soft Science.2004 (10)

[4]Rongshan Hu. Which Way Is China Modern ports Logistics Development[N]? China Water Transports newspaper.2009-5-14(5)

[5]Youfang Huang.ports Logistics Development Strategy\{J].Journal of Shanghai Maritime.2008,25(2).

[6]Haizhen Zhang. Logistics Park Development Model of Developed cities[EB/OL]. http://56economy.cn/info- view. asp?catalog=2638, 2010- 06- 04 .

[7]China F,federation of Logistics and Procurement,China Logistics Association.China Logistics Development Reports[M].Beijing:China material press,2010. 